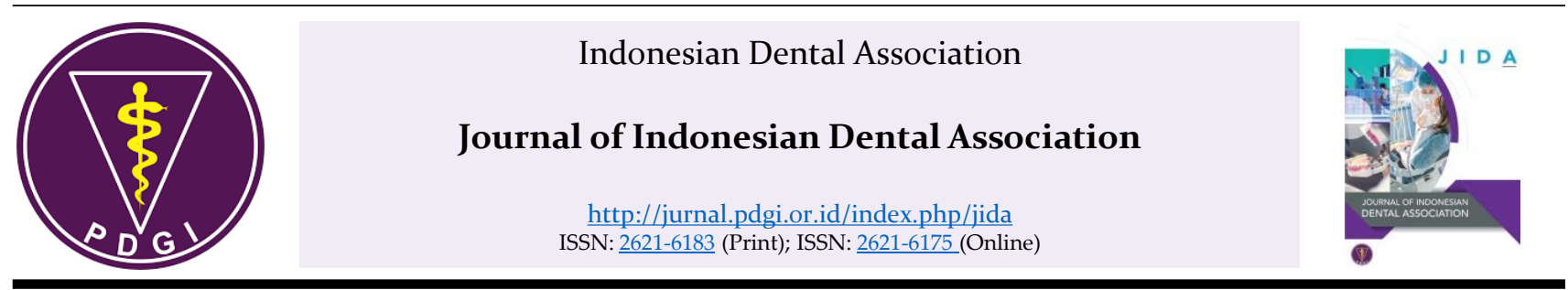

Research Article

\title{
The Effectiveness Differences \\ Between Watermelon (Citrullus \\ lanatus) Extract $100 \%$ and \\ Carbamide Peroxide Gel 10\% in Tooth Whitening (ex vivo)
}

\author{
Any Setyawati ${ }^{\S}$, Syifa Nabila Farah Fauziah Nur² \\ ${ }^{1}$ Dental Conservation, Dentistry Education Program, Faculty of Medicine and Health Sciences, Universitas Muhammadiyah \\ Yogyakarta, Indonesia \\ ${ }^{2}$ Dental School, Faculty of Medicine and Health Sciences, Universitas Muhammadiyah Yogyakarta, Indonesia
}

Received date: December 17, 2019. Accepted date: February 2, 2020. Published date: February 20, 2020.

\section{KEYWORDS \\ watermelon fruit extract carbamide peroxide gel; teeth whitening}

\begin{abstract}
Introduction: Discoloration can be caused by intrinsic or extrinsic factors. One of the discoloration treatments is teeth whitening. Teeth whitening process usually uses chemicals such as hydrogen peroxide or carbamide peroxide which can cause side effects, namely gingival irritation. Previous research has found that malic acid in strawberries can whiten teeth. Watermelons contain greater malic acid than strawberries. Objective: To analyze the effectiveness of $100 \%$ watermelon (Citrullus lanatus) extract on teeth whitening. Methods: The study was a laboratory experimental study with a total of 15 anterior post-extraction teeth which were discolored using black tea, divided into 3 groups. Group 1 was immersed in 100\% watermelon extract, group 2 was immersed in $10 \%$ carbamide peroxide as positive control and group 3 was immersed in sterile aquades as negative control, for 56 hours, measured using a shade guide and spectrophotometer. Data were analyzed using one way Anova. Results: The $100 \%$ watermelon extract was effective for teeth whitening. There was a significant difference between $100 \%$ watermelon extract compared to negative control $(p<0.05)$. However, there was also a significant difference between $100 \%$ watermelon extract, and $10 \%$ carbamide peroxide gel $(p=0.003)$. Conclusion: The watermelon extract has the ability as teeth whitening agent. However, further study is still needed to explore this result and determine the proper concentration for teeth whitening.
\end{abstract}




\section{KATA KUNCI}

ekstrak buah semangka; gel karbamid peroksida; pemutihan gigi

\section{PENDAHULUAN}

Diskolorasi adalah suatu keadaan warna gigi mengalami perubahan karena berbagai faktor penyebab baik ekstrinsik maupun instrinsik. Diskolorasi ekstrinsik dapat disebabkan oleh noda tembakau dan teh yang melekat pada permukaan gigi. Diskolorasi intrinsik dapat disebabkan oleh penggunaan obat tetrasiklin, trauma pada gigi, material restorasi gigi, material perawatan saluran akar, dan gangguan saat periode perkembangan gigi seperti amelogenesis imperfekta. ${ }^{1}$

Perawatan di kedokteran gigi yang dapat dilakukan untuk kasus diskolorasi adalah pemutihan gigi. Perkembangan pemutihan gigi telah terjadi kurang lebih selama 2000 tahun oleh seorang ahli. Pada sekitar tahun 1300 , memutihkan gigi adalah perawatan gigi yang paling banyak diminati selain pencabutan gigi ${ }^{2}$. Bahanbahan yang biasa digunakan untuk pemutihan gigi antara lain hidrogen peroksida, karbamid peroksida, dan natrium perborat. Teknik pemutihan gigi diklasifikasikan menjadi bleaching secara internal (pada gigi nonvital) dan bleaching secara eksternal (pada gigi vital). ${ }^{3}$ Penyebab diskolorasi gigi yang dapat berasal dari makanan dan minuman seperti teh, kopi, anggur merah, tembakau dan perubahan struktur pada dentin dan struktur email. ${ }^{4}$ Teknik bleaching secara internal meliputi teknik walking bleach dan teknik termokatalitik. ${ }^{1}$ Teknik bleaching secara eksternal meliputi teknik home bleaching dan teknik in-office bleaching. ${ }^{2}$ Penggunaan bahan pemutih gigi yang mengandung bahan kimia dapat menimbulkan beberapa efek samping, antara lain gigi sensitif yang umumnya terjadi dalam waktu singkat, iritasi pada mukosa gingiva dan tenggorokan menyebabkan nyeri, kerusakan pulpa, kerusakan jaringan keras gigi dan dapat menyebabkan resorbsi akar eksternal dan kebocoran mikro pada restorasi komposit. ${ }^{1,3}$

Saat ini banyak dilakukan penelitian mengenai pemanfaatan bahan alami pemutih gigi yang dianggap lebih aman, murah, dan mudah diperoleh dibandingkan bahan kimiawi. Asam malat dan asam elagat yang terkandung dalam buah-buahan dapat memutihkan gigi. ${ }^{5}$ Asam malat juga dapat membantu menjaga kebersihan mulut dan dapat digunakan untuk membersihkan email yang dilakukan oleh dokter gigi. ${ }^{6}$ Pada penelitian sebelumnya, diketahui apel mengandung asam malat yang terbukti dapat membantu melarutkan noda pada gigi. Selain apel, buah stroberi diketahui memiliki kandungan ellagic acid dan hidrogen peroksida yang dapat menyebabkan warna email menjadi lebih terang. 5,7

Buah semangka (Citrulluls lanatus) memiliki kandungan asam malat yang lebih besar yaitu $99 \%$, dibanding buah apel 95\%. Buah semangka juga mempunyai kandungan hidrogen peroksida seperti stroberi. Semangka memiliki suatu kandungan yang dapat menghilangkan noda dan pemutih gigi, yaitu asam malat dan hidrogen peroksida. Asam malat merupakan golongan asam karboksilat yang mempunyai kemampuan memutihkan gigi dengan cara mengoksidasi permukaan email gigi sehingga menjadi netral dan menimbulkan efek pemutihan. ${ }^{8}$

\section{BAHAN DAN METODE}

Penelitian ini termasuk jenis penelitian eksperimen laboratoris murni ex vivo. Subjek penelitian yang 
digunakan dalam penelitian ini adalah gigi insisif dan gigi kaninus sebanyak 15 gigi yang yang mahkotanya masih utuh, akar tidak perforasi, tidak karies dan tidak anomali. Pembuatan ekstrak buah semangka dilakukan di Laboratorium Farmasi Unit II GM dan tempat pengukuran intensitas cahaya atau spektrofotometer dilakukan di laboratorium teknik tekstil UII. Tahapan penelitian dibagi menjadi tahap persiapan dan tahap pelaksanaan.

\section{Tahap Persiapan}

Pembuatan larutan teh hitam untuk proses diskolorasi gigi, pemberian nomor urut pada seluruh sampel kemudian bagian akar diolesi cat kuku warna bening hingga bagian servikal. Sebelum diberi perlakuan, warna gigi-gigi tersebut diukur dengan menggunakan shade guide Vitapan Clasical. Tahap persiapan akhir adalah proses pembuatan ekstrak buah semangka. Semangka dipotong-potong, dikeringkan dengan oven, lalu diblender, selanjutnya dilakukan teknik ekstrak maserasi. Semangka yang digunakan pada penelitian ini adalah jenis round dragon dengan ciri berbiji, bentuk buah bulat agak oval, kulit buah hijau cerah berstrip hijau gelap, warna daging merah, rasa manis dan renyah. ${ }^{9}$

\section{Tahap Pelaksanaan}

Gigi-gigi dilakukan diskolorasi dengan direndam dalam larutan teh hitam, kemudian diukur warnanya dengan menggunakan shade guide agar dapat diketahui perbedaan atau perubahan sebelum dan sesudah dilakukan pemutihan gigi. Lima belas gigi tersebut yang telah diukur dengan shade guide selanjutnya dipersiapkan untuk pengukuran menggunakan spektrofotometer. Sebelum pengukuran dengan spektrofotometer, gigi diberi lakban hitam pada bagian akar gigi yang bertujuan untuk mengendalikan nilai pada spektrofotometer karena lakban hitam mempunyai nilai 0 (gelap), setelah diberi lakban hitam bagian akar gigi lalu dimasukkan ke dalam suatu plastik bening kecil dan diberi penomoran. Penembakan sinar pada spektrofotometer harus mengenai bagian mahkota gigi.

Kelompok 1 terdiri atas 5 gigi direndam dalam ekstrak semangka $100 \%$, kelompok 2 terdiri atas 5 gigi direndam dalam gel karbamid peroksida $10 \%$ dalam suatu wadah plastik selama 56 jam, kelompok 3 (kontrol) terdiri atas 5 gigi direndam dalam akuades steril, semuanya diletakkan dalam wadah plastik direndam selama 56 jam. Setiap pagi dan sore dilakukan penggantian larutan ekstrak semangka, gel karbamid peroksida dan larutan akuades (dengan diasumsikan pemakaian home bleaching adalah sehari 2 kali), selanjutnya dilakukan pengukuran menggunakan shade guide dan alat spektrofotometer. Warna shade guide dikoversikan dalam bentuk angka menggunakan alat spektrofotometer untuk mendapatkan data dalam bentuk angka sehingga mempermudah proses analisa data penelitian.

\section{Analisis Statistik}

Analisis statistik yang digunakan adalah statistik inferensial parametrik. Metode analisis yang digunakan merupakan data kuantitatif yang berupa bilangan atau angka yang mencerminkan nilai perubahan warna gigi. Metode analisis data menggunakan uji ANOVA satu jalan.

\section{HASIL}

Hasil menunjukkan bahwa terjadi perubahan warna gigi lebih putih setelah di aplikasikan dengan ekstrak semangka $100 \%$. Terdapat perbedaan yang signifikan antara ekstrak semangka $100 \%$ dibandingkan dengan kontrol negatif $(\mathrm{p}<0,05)$. Namun, ada juga perbedaan yang signifikan antara $100 \%$ ekstrak semangka, dan $10 \%$ karbamid peroksida gel $(\mathrm{p}=0,003)$.

Tabel 1 menunjukan terjadi perubahan nilai $\mathrm{dE}^{*} \mathrm{ab}$ pada kelompok sebelum dan sesudah dilakukan perendaman dalam gel karbamid peroksida $10 \%$ begitu juga dengan nilai shade guide yang mengalami perubahan meningkat menjadi lebih putih yaitu seperti contoh pada sampel 1 dari A3 menjadi B2.

Berdasarkan tabel 2 dapat dilihat terjadi perubahan nilai $\mathrm{dE}^{*} \mathrm{ab}$ pada kelompok sebelum dan sesudah dilakukan perendaman dalam ekstrak semangka $100 \%$ begitu juga dengan nilai shade guide yang mengalami peningkatan.

Tabel 3 yaitu kontrol negatif yang direndam dalam akuades steril yang digunakan sebagai pembanding diantara dua kelompok yang lain, terlihat perubahan hasil yang sangat kecil baik pada spektrofotometer maupun shade guide, bahkan cenderung sama tidak mengalami perubahan apapun. Berdasarkan Tabel 4 dapat dilihat selisih nilai $\mathrm{dE}^{*} \mathrm{ab}$ sebelum dan sesudah perendaman.

Berdasarkan hasil uji normalitas diatas, penyebaran data pada ketiga kelompok adalah normal, karena nilai $p$ $>0,05$. Untuk menguji hipotesis, dilakukan uji parametrik ANOVA satu jalan.

Nilai warna gigi berdasarkan Saroea 2008 yaitu: ${ }^{10}$

$$
\mathrm{dE}^{*} \mathrm{ab}=\left\{\left(\mathrm{L}^{*}\right)^{2}+\left(\mathrm{a}^{*}\right)^{2}+\left(\mathrm{b}^{*}\right)^{2}\right\}^{1 / 2}
$$

$\mathrm{L}^{*}=$ ukuran suatu kecerahan benda (0-100) / (0-256)

$\mathrm{a}^{*}=$ ukuran kemerahan $(\mathrm{a}>0)$ atau kehijauan $(\mathrm{a}<0)$

$\mathrm{b}^{*}=$ ukuran kekuningan $(\mathrm{b}>0)$ atau kebiruan $(\mathrm{b}<0)$ 
Tabel 1. Data nilai dE*ab sebelum dan sesudah perendaman gel karbamid peroksida $10 \%$.

\begin{tabular}{ccccc}
\hline & \multicolumn{4}{c}{ Gel Karbamid Peroksida 10\% } \\
\cline { 2 - 5 } Sampel No & \multicolumn{2}{c}{ Sebelum Perendaman } & \multicolumn{2}{c}{ Setelah Perendaman } \\
\cline { 2 - 5 } & Shade Guide & Spektrofotometer & Shade Guide & Spektrofotometer \\
\hline 1 & A3 & 108,96 & B2 & 128,01 \\
2 & A3 & 114,17 & B2 & 127,17 \\
3 & B3 & 94,08 & D2 & 121,79 \\
4 & A3 & 113,91 & B1 & 140,49 \\
5 & A3 & 105,35 & B2 & 128,30 \\
\hline
\end{tabular}

Tabel 2. Data nilai dE*ab sebelum dan sesudah perendaman ekstrak semangka $100 \%$.

\begin{tabular}{ccccc}
\hline \multirow{2}{*}{ Sampel No } & \multicolumn{4}{c}{ Ekstrak Semangka 100\% } \\
\cline { 2 - 5 } & \multicolumn{2}{c}{ Sebelum Perendaman } & \multicolumn{2}{c}{ Setelah Perendaman } \\
\cline { 2 - 5 } & Shade Guide & Spektrofotometer & Shade Guide & Spektrofotometer \\
\hline 6 & B4 & 91,50 & D3 & 115,39 \\
7 & B3 & 95,29 & A1 & 140,02 \\
8 & A4 & 83,91 & B2 & 129,88 \\
9 & B4 & 91,38 & A2 & 122,72 \\
10 & A3 & 104,63 & D2 & 124,52 \\
\hline
\end{tabular}

Tabel 3. Data nilai $\mathrm{dE}^{*} \mathrm{ab}$ sebelum dan sesudah perendaman dalam akuades steril sebagai kontrol negatif.

\begin{tabular}{ccccc}
\hline \multirow{2}{*}{ Sampel No } & \multicolumn{4}{c}{ Akuades Steril (Kontrol Negatif) } \\
\cline { 2 - 5 } & \multicolumn{2}{c}{ Sebelum Perendaman } & \multicolumn{2}{c}{ Setelah Perendaman } \\
\cline { 2 - 5 } & Shade Guide & Spektrofotometer & Shade Guide & Spektrofotometer \\
\hline 11 & B3 & 98,71 & B3 & 91,36 \\
12 & B3 & 98,31 & B3 & 100,14 \\
13 & A4 & 84,63 & A4 & 85,43 \\
14 & B4 & 92,49 & B4 & 95,72 \\
15 & A4 & 81,38 & A4 & 82,08 \\
\hline
\end{tabular}

Tabel 4. Data selisih nilai $\mathrm{dE}^{*}$ ab setelah dan sebelum perendaman gigi

\begin{tabular}{cccccc}
\hline \multicolumn{5}{c}{ Bahan Bleaching } \\
\hline \multicolumn{5}{c}{ Karbamid Peroksida 10\% } & \multicolumn{2}{c}{ Ekstrak Semangka 100\% } & \multicolumn{2}{c}{ Akuades Steril } \\
\hline No. Sampel & Nilai Selisih & No. Sampel & Nilai Selisih & No. Sampel & Nilai Selisih \\
\hline 1 & 19,05 & 6 & 23,89 & 11 & $-7,35$ \\
2 & 13,00 & 7 & 44,73 & 12 & 1,83 \\
3 & 27,71 & 8 & 45,97 & 13 & 0,8 \\
4 & 26,58 & 9 & 31,34 & 14 & 3,23 \\
5 & 22,95 & 10 & 19,89 & 15 & 0,70 \\
\hline
\end{tabular}


Hasil pengukuran dengan menggunakan spektrofotometer memiliki nilai yang berbeda-beda pada setiap sampel, hasil tersebut didapat dari nilai jarak $\mathrm{L}^{*}$, $a^{*}, b^{*}$ sehingga didapat nilai $\mathrm{dE}^{*} \mathrm{ab}$ yaitu besarnya intensitas warna yang diserap setiap sampel.

\section{PEMBAHASAN}

Hasil penelitian pada kelompok gigi yang direndam dalam ekstrak semangka 100\%, dan kelompok dengan direndam dalam gel karbamid peroksida $10 \%$ terjadi perubahan nilai $\mathrm{dE}^{*} \mathrm{ab}$ pada pengukuran dengan spektrofotometer yaitu memiliki nilai lebih besar setelah perendaman. Hal ini sesuai dengan penelitian sebelumnya yang dilakukan oleh Sluzker bahwa pada benda yang mempunyai daya kilau dan bersifat solid seperti gigi, maka angka sinar yang dipantulkan akan dibelokkan sehingga penyerapan warna lebih sedikit. Semakin sedikit sinar yang dipantulkan maka penyerapan warna akan semakin besar yang berarti warna gigi menjadi lebih putih. ${ }^{11}$

Perbedaan rata-rata antara kelompok yang direndam dalam ekstrak semangka 100\%, kelompok yang direndam dalam gel karbamid peroksida 10\% dan kelompok yang direndam dalam akuades steril, tingkat signifikansi 0,05 dan taraf kepercayaan 95\% $(\alpha=0,05)$. Hasil perbedaan kelompok ekstrak semangka dan kelompok gel karbamid peroksida memiliki nilai siginifikansi $p=0,003$ dan nilai $p<0,05$ yang berarti terdapat perbedaan yang signifikan antara kelompok yang direndam dengan ekstrak semangka dan kelompok yang direndam dengan gel karbamid peroksida.

Hasil penelitian ini menunjukkan bahwa ekstrak semangka $100 \%$ dapat memutihkan gigi. Kandungan Kandungan dalam buah semangka yaitu asam malat merupakan golongan asam karboksilat yang dapat memutihkan gigi dengan cara mengoksidasi permukaan email sehingga menjadi netral dan menimbulkan efek pemutihan ${ }^{5}$, Hal ini sesuai dengan penelitian Pramesti yang membuktikan bahwa asam malat dalam strawberry dapat memutihkan gigi yang terkena noda kopi ${ }^{7} \mathrm{Hal}$ ini juga sesuai dengan penelitian yang dilakukan Puspasari bahwa kandungan asam malat dalam apel dapat membantu melarutkan noda pada gigi. ${ }^{12}$ Buah semangka (Citrulluls lanatus) memiliki kandungan asam malat yang tinggi yaitu 99\%, dan kandungan asam malat yang terbesar selain pada semangka adalah apel $95 \%$ dari total seluruh asam pada buah tersebut. Asam malat merupakan golongan asam karboksilat yang mempunyai kemampuan memutihkan gigi dengan cara mengoksidasi permukaan email gigisehingga menjadi netral dan menimbulkan efek pemutihan ${ }^{5}$. Dalam penelitian ini gel karbamid peroksida $10 \%$ lebih efektif untuk pemutihan gigi. Perendaman sampel dalam gel karbamid peroksida $10 \%$ memiliki hasil pemutihan gigi yang lebih tinggi dibandingkan dengan kelompok yang direndam dalam ekstrak semangka 100\%, menurut Cabarello, karbamid peroksida merupakan salah satu bahan kimia di kedokteran gigi yang biasa digunakan sebagai bahan home bleaching dengan kandungan hidrogen peroksida sebesar 3,5\% dan urea $6,5 \%$ yang tentunya akan menyebabkan gigi menjadi lebih putih dibandingkan bahan pemutih gigi yang alami, semakin tinggi konsentrasi dan durasi pengaplikasian bahan bleaching maka akan semakin cepat pula efek pemutihan pada gigi. ${ }^{13}$

Penelitian sebelumnya yang dilakukan oleh Rivero, menunujukkan adanya aktifitas enzim polifenol oksidase dan peroksidase pada semangka yang lebih tinggi dibanding tomat. Hidrogen peroksida yang terdapat dalam semangka berperan sebagai oksidator kuat yang menghancurkan agen penghasil warna gigi penyebab diskolorasi dengan cara membebaskan radikal bebas atau oksigen aktif ke permukaan email dan dentin sehingga menyebabkan ikatan konjugasi pada zat penyebab diskolorasi gigi rusak, kemudian gigi dapat menjadi putih. ${ }^{14}$ Kadar hidrogen peroksida dalam satu buah tomat sekitar $4000 \times 10^{-9} \mathrm{~mol}$ yang dapat dimanfaatkan sebagai bahan pemutihan gigi yang mengalami perubahan warna. ${ }^{15}$

Reaksi yang terjadi pada proses pemutihan gigi disebut dengan reaksi oksidasi, reaksi ini menggunakan hidrogen peroksida yang terdapat pada buah semangka berperan sebagai oksidator kuat yang berperan untuk memutihkan gigi. Kandungan lain dalam buah semangka yaitu asam malat merupakan golongan asam karboksilat yang mempunyai kemampuan memutihkan gigi sama seperti hidrogen peroksida yaitu dengan cara mengoksidasi permukaan email sehingga menjadi netral dan menimbulkan efek pemutihan. ${ }^{16}$

\section{KESIMPULAN}

Ekstrak semangka memiliki kemampuan sebagai bahan pemutih gigi. Namun, penelitian lebih lanjut masih diperlukan untuk mengeksplorasi hasil ini dan menentukan konsentrasi semangka yang tepat untuk memutihkan gigi sehingga dapat dibandingkan dengan gel karbamid peroksida.

\section{KONFLIK KEPENTINGAN}

Tidak ada.

\section{DAFTAR PUSTAKA}

1. Grossman L, Oliet S, Del Rio C, Ilmu endodontik dalam praktek. Ed 11. Jakarta: EGC; 1995.

2. Ascheim K, Dale B, Esthetic dentistry: A clinical 
approach to techniques and material. $2^{\text {nd }}$ ed. St. Louis(MO): Elsevier/Mosby; 2011.

3. Walton RE, Tarobinejad M. Prinsip dan praktek ilmu endodonsi. Ed 3. Jakarta: EGC; 2008.

4. Brenna F. Restorative dentistry: Treatment procedures and future prospects. St. Louis (MO): Elsevier/Mosby; 2011.

5. Margaretha J, Rianti D, Meizarini A. Effect of strawberry paste and carbamide peroxide gel $10 \%$ towards the brightness enamel tooth. Mater Dent $\mathbf{J}$ FKG UNAIR. 2008;1(1):2009-01.

6. Fauziah D. Colour change of enamel after application Averrhoa blimbi. J Dent Indonesia. 2012;19(3):53-6.

7. Pramesti A, Jasrin TA, Hidayat OT. Teeth rewhitening effect of strawberry juice on coffee stained teeth. Padjajaran Journal of Dentistry. 2013;25(1):15-20.

8. Octarina, Aprilianti E. The effect of citrus limon and whitening toothpaste to teeth color changes (study on the right maxillary central incisor of 18 year old female). In: Proceedings of The International Dental Conference of Sumatera Utara: Advances in Health Sciences Research [Conference Proceedings on the Internet]; 2017 Dec 7-9; North Sumatera. Beijing: Atlantis Press; 2017.

9. Wihardjo S. Bertanam semangka. Yogyakarta: Kanisius; 1993.
10. Ariana TR, Wibisono G, Praptiningsih RS. Pengaruh perasan buah lemon terhadap peningkatan warna gigi. Media Dental Intelektual. 2015; 2(1):74-78

11. Sluzker A, Knosel M, Athanasiou AE. Sensitivity of digital dental photo CIE $\mathrm{L}^{*} \mathrm{a} \mathrm{b}^{*}$ analysis compared to spectrophotometer clinical assessments over 6 months. Am J Dent. 2011;24(5):300-4.

12. Puspasari N, Effendi M, Nugraeni Y. Pengaruh pemberian jus apel (Malus sylvestris Mill.) varietas anna pada gigi yang telah direndam larutan kopi terhadap pemutihan gigi secara in vitro. Insisiva Dent J: Majalah Kedokteran Gigi Insisiva. 2012;1(2):17-19.

13. Caballero AB, Navarro LF, Lorenzo JA. At home vital bleaching: A comparison of hydrogen peroxide and carbamide peroxide treatment. Med Oral Patol Oral Cir Bucal. 2006;11:E94-E99.

14. Rivero D. Resistence to cold and heat stress: Accumulation of phenolic compunds in tomato and watermelon plants. Plant Sci. 2001;160:3015-321.

15. Saputro B. Pengaruh konsentrasi jus buah tomat (Lycopersicon esculentum Mill.) terhadap perubahan warna gigi dalam proses pemutihan gigi secara in vitro [Skripsi]. Semarang: Fakultas Kedokteran Universitas Diponegoro; 2009.

16. Joiner A. The bleaching of teeth: A review of the literature. J Dent. 2006;34:412-419. 